\title{
0 ritual de hospitalidade na escola de samba Camisa Verde e Branco
}

The hospitality ritual in the Camisa Verde e Branco samba school El ritual de la hospitalidad en la escuela de samba Camisa Verde e Branco http://dx.doi.org/10.18472/cvt.16n1.2016.1043

Fernanda Schmidt Marques 〈fernandacsmarques@gmail.com >

Mestre em Hospitalidade pela Universidade Anhembi Morumbi (UAM), São Paulo, SP, Brasil.

Sênia Bastos 〈senia@anhembimorumbi.edu.br >

Professora titular da Universidade Anhembi Morumbi (UAM), São Paulo, SP, Brasil.

CRONOLOGIA DO PROCESSO EDITORIAL

Recebimento do artigo: 24-abr-2015

Aceite: 07-abr-2016

FORMATO PARA CITAÇÃO DESTE ARTIGO

MARQUES, F. S.; BASTOS, S. O ritual de hospitalidade na escola de samba Camisa Verde e Branco. Caderno Virtual de Turismo. Rio de Janeiro, v. 16 n. 1, p. 95-108, abr. 2016.

REALIZAÇÃO

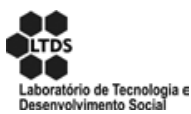

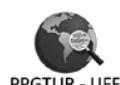

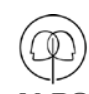

IABS
APOIO INSTITUCIONAL

COPPE

UFR]

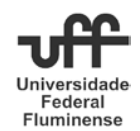

EDIÇÃO

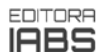

PATROCÍNIO

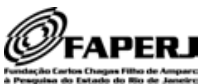




\section{RESUMO}

A hospitalidade é entendida como um gesto de reciprocidade e como a relação entre visitantes e anfitriões, caracterizando-se como um encontro marcado pela atitude de acolhimento ao outro. É ela quem autoriza a passagem do exterior para o interior. Este artigo possui como objetivo analisar o ritual de hospitalidade na escola de samba Camisa Verde e Branco, agremiação mais antiga da cidade de São Paulo, que surgiu em 1914 como um grupo carnavalesco. Esta é uma pesquisa qualitativa de abordagem etnográfica cujos métodos de coleta de dados incluíram anotações no caderno de campo, registros fotográficos, realização de entrevistas semiestruradas e convivência com a escola. A quadra de ensaios da referida escola é um local de encontro, de convivialidade e de sociabilidade para seus membros e os eventos lá realizados contribuem para a criação e para o reforço dos laços sociais. No ritual da hospitalidade, os turistas, embora admitidos no interior da quadra, não são acolhidos nem integrados, já que a atividade do anfitrião não é exercida.

Palavras-chave: Hospitalidade. Sociabilidade. Escola de samba.

\section{ABSTRACT}

Hospitality is understood as a gesture of reciprocity and as the relationship between hosts and guests, being characterized as an encounter marked by the welcoming attitude towards others. It is what allows the passage from the outside to the inside. This paper aims to analyze the hospitality ritual in the Camisa Verde e Branco samba school, the oldest in São Paulo that emerged in 1914 as a carnival group. This is a qualitative research with an ethnographic approach, in which records in the field notebook, photographic records, semi-structured interviews and a time spent within the community were used as data collection method. The school's rehearsal court works as a meeting, a conviviality and a sociability place for its members and the events that take place there contribute to the creation and the strengthening of social ties. In the hospitality ritual, the tourists, besides admitted inside the court, are not welcomed nor integrated, once the host activity is not exercised.

Keywords: Hospitality. Sociability. Samba school.

\section{RESUMEN}

La hospitalidad es entendida como un gesto de reciprocidad y como la relación entre el visitantes y anfitriones, que se caracteriza como um encuentro marcado por la actitud de acogida del otro. Es lo que permite el paso desde el exterior hacia el interior. Este trabajo tiene como objetivo analizar el ritual de la hospitalidad en la escuela de samba Camisa Verde e Branco, la más antigua de São Paulo, que surgió en 1914 como un grupo de carnaval. Se trata de un enfoque de investigación cualitativa etnográfica cuyo método de recolección de datos incluiyó notas en el cuaderno de campo, registros fotográficos, realización de entrevistas semi-estruradas y la convivencia con la escuela. La corte de la escuela es un lugar de encuentro, de convivencia y de sociabilidad para sus miembros y los eventos realizados allí contribuem para la creación y el fortalecimiento de los vínculos sociales. En el ritual de la hospitalidad, los turistas, mismo que admitidos en el interior de la corte, no son bienvenidos ni integrados, ya que la actividad del anfitrión no es ejercida.

Palabras claves: Hospitalidad. Sociabilidad. Escuela de samba.

\section{Observação:}

- A presente reflexão integra a dissertação de mestrado intitulada "As práticas de hospitalidade na escola de samba Camisa Verde e Branco", que foi defendida em fevereiro de 2015. 


\section{Introdução}

O conceito de hospitalidade adotado fundamenta-se na teoria da dádiva de Mauss, a qual proporciona a base para se entender as relações de sociabilidade e de acolhimento. Marcel Mauss, sociólogo e antropólogo francês, analisou as formas de contrato e o sistema de trocas e de prestações econômicas de sociedades arcaicas e concluiu que existe, ao mesmo tempo, uma liberdade e uma obrigação de dar e receber, assim como uma liberdade e uma obrigação de retribuir (MAUSS, 2003 apud PIMENTEL et al, 2007). Falar em dádiva é, segundo Bueno (2008), falar em pactos e vínculos sociais entre as pessoas. A dádiva desencadeia o processo de hospitalidade, mas nem toda dádiva insere-se dentro dela. A hospitalidade é entendida como as relações sociais entre visitantes e anfitriões e caracteriza-se como um encontro entre as pessoas, marcado pela atitude de acolhimento ao outro.

O objetivo deste trabalho é analisar o ritual da hospitalidade na Associação Cultural e Social Escola de Samba Mocidade Camisa Verde e Branco, agremiação carnavalesca pertencente ao Grupo de Acesso do carnaval paulistano. Analisar um lugar sob a ótica da hospitalidade implica em centrar a abordagem na perspectiva do anfitrião e, nesse caso, recai na análise de como a comunidade recebe e como se relaciona com os turistas. São entendidos como anfitriões os membros da comunidade envolvidos com a recepção de visitantes na sede social e quadra da agremiação, de maneira direta ou indireta; e são tidos como visitantes os moradores da região, os turistas e demais pessoas que, constantemente ou não, frequentam o local e consomem os produtos ou serviços oferecidos.

O conceito de turista aqui utilizado não é o usual do trade, segundo o qual o turismo caracteriza-se pelo deslocamento de indivíduos ou grupos para um local que não seja o de sua residência por um período de mais de 24 horas. Nesse caso, há sobreposição do turista em seu conceito usual com aquele que não pertence à comunidade e também com o forasteiro que participa somente por ocasião do desfile carnavalesco.

A agremiação foi escolhida baseada no critério de tempo de existência: é a mais antiga da cidade de São Paulo e surgiu em 1914 como Grupo Carnavalesco da Barra Funda, o qual saía pelas ruas do bairro de mesmo nome sob a liderança de Dionísio Barbosa (CAMISA, 2014). O grupo da Barra Funda foi o embrião do atual Camisa Verde e Branco, escola cuja quadra de ensaios é um lugar de encontro, de convívio, de recreação e de sociabilidade para sua comunidade, que se reúne frequentemente no local. A participação das pessoas é baseada em sentimentos de reciprocidade, de cooperação e solidariedade, já que, salvo algumas exceções, os cargos não são remunerados e as ações são desenvolvidas pelo amor ao pavilhão e motivadas pelo desejo que a escola saia vitoriosa no próximo carnaval, pela amizade e união do grupo.

As reflexões neste artigo originaram-se de uma pesquisa qualitativa, apoiada na pesquisa bibliográfica e etnográfica. Foi realizada uma pesquisa bibliográfica sobre hospitalidade, carnaval e escolas de samba e a etnografia consistiu em um trabalho de campo realizado entre maio de 2013 e janeiro de 2015, o qual incluiu: visitas à quadra da escola de samba Camisa Verde e Branco, participação nos ensaios para os carnavais de 2014 e 2015 - que aconteceram na quadra, na rua e no Sambódromo do Anhembi entre julho de 2013 e fevereiro de 2014 e entre julho de 2014 e fevereiro de 2015 -, participação em eventos promovidos pela agremiação, realização de conversas, de entrevistas semiestruturadas e análise das informações e coleta de dados e fotos contidos no site oficial da agremiação e no Facebook.

Constatou-se que a comunidade abriga, em seu interior, um grupo menor e mais restrito que é conhecido como família. A palavra família é usada, neste trabalho, em sentido figurado e refere-se a um núcleo 
existente no interior da comunidade do Camisa Verde e Branco, no qual os vínculos sociais são ainda mais sólidos do que os dos demais membros.

\section{Hospitalidade}

A hospitalidade, comumente associada ao turismo e aos meios de hospedagem, possui sua "origem" na antiguidade, época que era considerada um dever sagrado e possuía a finalidade de acolher os estrangeiros que se encontravam longe de seu local de origem. Suas definições atravessam diversos campos de análise e, em todos eles, ela é analisada considerando o acolhimento, o encontro entre visitantes e anfitriões e a relação humana dele resultante. Dessa forma, segundo Pimentel et al. (2007), ela está relacionada à relação social, aos vínculos e à dádiva. Suas práticas visam ordenar as tensões e limitar a hostilidade, e seus gestos criam laços sociais e pessoais. A hospitalidade não pode ser forçada, seus gestos são voluntários e o retorno não deve ser cobrado (FRIESE, 2009).

A hospitalidade é entendida como um gesto de reciprocidade e acarreta o ingresso no espaço do anfitrião e o início de um ritual de acolhida. Ela pressupõe uma desigualdade de lugar e de estatuto, entre aquele que recebe e aquele que é recebido: um é o anfitrião, dono da casa, e está no interior e o outro, que é recebido, está de passagem e encontra-se no exterior. A passagem do exterior para o interior supõe uma autorização e/ou um convite e é justamente a hospitalidade que controla essa passagem e que permite a transposição do limite sem se valer da violência. Ela é caracterizada pela troca no relacionamento construído entre o visitante e o anfitrião e depreende uma continuidade, visto que o anfitrião de hoje pode se tornar o visitante de amanhã (GRASSI, 2004; RAFFESTIN, 1997).

Esse limite pode ser material - a entrada em um espaço geográfico - ou imaterial - a entrada no território do outro. O limite material é constituído pelas fronteiras que demarcam um território e que determinam os espaços autorizados e também os proibidos, nos quais o visitante é indesejado e sua entrada não é permitida; já o limite imaterial controla o uso do espaço partilhado e é composto por códigos e valores que somente possuem sentido no interior. A fronteira imaterial é mais difícil de transpor do que a fronteira material e é nela que se fará a aceitação ou rejeição do forasteiro. O interior é o espaço onde não há comunicação por desconhecimento dos códigos do outro, do estrangeiro, tornando-se necessária a tradução desses símbolos para que a comunicação e o contato sejam possíveis. No caso do Camisa Verde e Branco, o limite material seria a porta de entrada na quadra e a transposição do limite imaterial significa ser aceito no interior da comunidade. O visitante - nesse caso, o turista - não aceito no interior, embora esteja presente na quadra, é mantido à margem da comunidade e torna-se um refém (RAFFESTIN, 1997).

Após ser admitido em uma comunidade, o forasteiro, segundo Pitt-Rivers (2012) e Gotman (2008), adquire dívidas e obrigações e é sempre avaliado, devendo se submeter, de alguma forma, a uma provação. $\mathrm{O}$ anfitrião possui direitos e deveres em relação ao visitante, cujos direitos e obrigações são respeitar e honrar seu hospedeiro e retribuir a hospitalidade em outra ocasião, em outro tempo e em outro espaço, em uma alternância de papéis. As leis da hospitalidade são decorrentes da necessidade sociológica e de acordo com elas, a relação entre visitante e anfitrião deve obedecer a regras universais, cujos detalhes referentes à sua violação variam de acordo com o lugar e a cultura das pessoas. O visitante deve honrar seu anfitrião, aceitar o que lhe for oferecido - principalmente a comida, já que a ingestão de alimentos e bebidas em conjunto cria um vínculo - e não usurpar o papel de seu anfitrião, pois este é quem detém o controle 
das regras. O anfitrião, por sua vez, deve honrar seu visitante, protegê-lo, defendê-lo e oferecer sempre o melhor que puder. A lei da hospitalidade está fundada na ambivalência; ela impõe ordem e faz com que o desconhecido se torne conhecido. As funções de visitante e de anfitrião possuem limitações territoriais: o anfitrião somente desempenha esse papel em uma ocasião ou local no qual ele posssua autoridade e o visitante não pode sê-lo em um espaço onde tenha direitos e responsabilidades (PITT-RIVERS, 2012).

Antigamente, o estrangeiro não possuía status na lei nem na religião e para obter a proteção das leis e dos deuses, deveria possuir um patrono, sendo admitido e incorporado na comunidade somente por meio de um vínculo pessoal com um membro estabelecido (COULANGES, 1895 apud PITT-RIVERS, 2012). Sua posição social em sua sociedade de origem não é, necessariamente, aceita em outra e, ao ser aceito em uma nova comunidade, ele recomeça como indivíduo. Entretanto, uma vez que é o local de nascimento que define a natureza essencial do indivíduo, um forasteiro pode nunca ser incorporado por completo. Muitos povos recusavam-se a integrar qualquer pessoa que fosse incapaz de comprovar uma ligação de parentesco com a tribo e tratavam o forasteiro como um bandido que poderia ser penalizado ou destruído impunemente, pois, mesmo quando não fosse suspeito, ele era potencialmente hostil (PITT-RIVERS, 2012).

\section{O carnaval e o camisa verde e branco}

O carnaval possui seu começo relacionado ao entrudo, uma festa portuguesa que consistia em brincadeiras de rua nas quais as pessoas jogavam água, ovos, farinha e outros líquidos umas nas outras. O folguedo possuía um significado relacionado à liberdade - sentido que permanece até os dias de hoje no carnaval - e eram comuns o consumo exagerado de comidas e bebidas, danças e zombarias públicas (QUEIROZ, 1999; SEBE, 1986; SIMSON, 2007).

O entrudo acontecia nos dias que antecediam a quaresma, do sábado gordo à quarta-feira de cinzas, as brincadeiras obedeciam a limitações de sexo e idade e era inaceitável o revide por parte dos escravos. Com pequenas variações, o entrudo foi a principal manifestação de carnaval no Brasil durante o período do Reinado e do Primeiro Império, de acordo com Britto (1986). Os folguedos foram se modificando e adquirindo características particulares devido à influência de elementos das diferentes culturas dos povos que habitavam o Brasil e, como consequência, em cada cidade, o carnaval possui, hoje, características específicas que condizem com os costumes locais. Em Salvador, predominam os trios elétricos e blocos de afoxés; em Olinda e Recife, os blocos de frevo e maracatu; na cidade de São Luiz do Paraitinga, em São Paulo, há as marchinhas; no Rio de Janeiro e em São Paulo são comuns os desfiles das escolas de samba (SIMSON, 2007).

Os cordões carnavalescos foram os embriões das atuais escolas de samba paulistanas. Eles desfilavam nas principais ruas de seus bairros de origem durante os dias de carnaval, se caracterizavam como um prolongamento das relações de vizinhança e parentesco e organizavam excursões e romarias à cidade de Pirapora e atividades de lazer para a população negra da cidade. Os cordões foram a expressão mais forte do carnaval de São Paulo e resistiram até mesmo após a criação das primeiras escolas de samba nos anos 1930 (BRITTO, 1986; SIMSON, 2007).

O primeiro cordão foi o Grupo Carnavalesco da Barra Funda, que, liderado por Dionísio Barbosa, se originou em 1914 no Largo da Banana, próximo à linha férrea Sorocabana, na Barra Funda, bairro da zona 
oeste de São Paulo. O grupo era composto por oito homens que, uniformizados, ensaiavam e desfilavam pelas ruas do bairro, cantando músicas de autoria própria, acompanhadas de violões, pandeiros e chocalhos de tampinhas de cerveja. Entre 1918 e 1919, o cordão já contava com cerca de cinquenta componentes, que desfilavam de calça branca (pois todos possuíam uma), camisa verde (fornecida pela direção do bloco) e chapéu de palha, indumentária que lhe rendeu o apelido de Camisa Verde. Mais tarde, por imposição policial, tiveram que acrescentar o branco, para diferenciarem-se do movimento integralista de Plínio Salgado (CAMISA, 2014; OBSERVATÓRIO, 2014a; SIMSON, 2007).

O Barra Funda foi influenciado pelos ranchos cariocas - manifestações carnavalescas populares cujos componentes desfilavam fantasiados ao som da marcha-rancho - e pelos folguedos negros do interior do Estado de São Paulo, como o samba rural ou samba de bumbo (BELO, 2008; SIMSON, 2007). O grupo parou de desfilar em 1936 devido às perseguições sofridas durante a Era Vargas (1930 a 1945) e em 1953, Inocêncio Tobias, o Mulata, reorganizou o antigo grupo carnavalesco e fundou o "Cordão Mocidade Camisa Verde e Branco". Em 1972, o Camisa Verde e Branco se tornou uma escola de samba, inaugurou sua quadra de ensaios na Barra Funda e ingressou no primeiro grupo do carnaval paulistano. Em 1977, conquistou o título de tetracampeão e em 1980, com o falecimento de Inocêncio Tobias, seu filho, Carlos Alberto Tobias, assumiu a presidência da agremiação, apoiado por sua mãe, Dona Sinhá, e por sua esposa Magali dos Santos.

Sua sede social e quadra de ensaios está localizada na Rua James Holland, 663, no bairro da Barra Funda, próxima à estação de trem e metrô Palmeiras-Barra Funda e à Avenida Marquês de São Vicente. O barracão de alegorias localiza-se na Rua Sólon, no bairro do Bom Retiro, embaixo do viaduto Orlando Murgel. As cores oficiais são o verde e o branco, o orixá é Ogum e o símbolo é um trevo de quatro folhas na cor verde, que é utilizado para identificar a agremiação nas redes sociais, nas roupas e nos instrumentos. $\mathrm{O}$ pavilhão é composto pelo trevo na cor verde com o nome da escola, sua data de fundação e nove estrelas na cor dourada que representam os campeonatos conquistados nos desfiles oficiais das escolas de samba (CAMISA, 2014).

A escola possui, além do site, um aplicativo para celular e perfis nas redes sociais Twitter(@CamisaVerde) e Facebook (Camisa Verde e Branco - Oficial), onde são divulgados eventos e ensaios. Os anúncios e as divulgações de eventos nas redes sociais convidam a família e os amigos a irem à quadra e se iniciam com saudações como "Alô, Comunidade!", "Alô, Compositores!" ou "Alô, Camisa" e terminam com "Salve" ou "Axé". Essas saudações são comumente utilizadas durante os ensaios na quadra e, nas redes sociais, os membros da agremiação são referidos como quem é "do trevo", "verde e branco" ou da "Barra Funda". Os eventos restritos à comunidade não são anunciados nas redes sociais, no site ou no aplicativo e são divulgados por meio de ligações telefônicas e mensagens de texto no celular.

\section{Metodologia}

Foi realizada uma pesquisa bibliográfica sobre os temas carnaval, escolas de samba, hospitalidade e sobre o Camisa Verde e Branco com a finalidade de perceber a função social do carnaval como formador de vínculos e identidade grupal e a importância da quadra de ensaios no ritual da hospitalidade.

A etnografia consiste no estudo de um objeto por meio da vivência direta no meio onde ele está inserido. Requer "as qualidades de observação, de sensibilidade, de inteligência e de imaginação científica do 
observador", resultando na "escrita do visível", ou seja, no relato minucioso das situações observadas, sensações encontradas, gestos, expressões corporais, silêncios, sorrisos, ruídos, entre outros (LAPLANTINE, 2004, p. 10). Nesse caso, o objeto de estudo é a comunidade da escola de samba paulistana Camisa Verde e Branco e o trabalho de campo referente a esta pesquisa foi desenvolvido por meio do convívio com a agremiação (de maio de 2013 a fevereiro de 2015) e da participação em ensaios, festas e eventos da agremiação, realizados na quadra de ensaios ou no Sambódromo. O método etnográfico se tornou necessário porque o comportamento das pessoas é baseado em conhecimentos tácitos, o que dificulta sua análise somente mediante entrevistas, ainda mais se tratando do comportamento relacionado à hospitalidade. Foi necessário conviver com a comunidade e observá-la a fim de entender como ela funciona. De acordo com Severino (2007), o pesquisador, ao se inserir na comunidade, irá compartilhar as vivências e o cotidiano e registrar suas observações em um caderno de campo. No entanto, o trabalho de campo não existe por si só, ou seja, não basta apenas estar com o objeto de pesquisa, é preciso conviver com ele e se inserir em seu meio social.

As técnicas de pesquisa utilizadas foram a observação participante e a realização de sete entrevistas semiestruturadas. A produção dos dados apoiou-se na descrição de como a escola de samba recebe a família e os turistas e nos comportamentos da comunidade, sem, contudo, nenhuma interferência e respeitando os hábitos, a privacidade e a alteridade. Para as conversas e as entrevistas foi utilizada uma técnica conhecida popularmente como "bola de neve", na qual cada entrevistado sugere outro componente para ser entrevistado. Os entrevistados foram escolhidos com base no tempo de participação na escola de samba e também pela frequência com que participam dos eventos. O recrutamento de novos entrevistados foi interrompido após o corpus de pesquisa ter atingido a saturação, com discursos repetitivos sobre as questões abordadas (BAUER; AARTS, 2002).

Como fonte de coleta de dados foram utilizados: a fala espontânea das pessoas, anotações feitas em campo, fotografias tiradas pela autora, análise de fotos e publicações dos membros e da agremiação na rede social Facebook, conversas e entrevistas com os membros da família.

\section{A sociabilidade e o ritual da hospitalidade no camisa verde e branco}

Assim como o carnaval, a hospitalidade altera as hierarquias existentes. No carnaval, era concedida uma licença que autorizava a desordem carnavalesca: o rei era deposto e um novo rei era eleito pelo povo, o Rei Momo; na hospitalidade, o estranho é elevado à posição de convidado e, então, honrado e o anfitrião é quem presta serviços para o outro. Há outras semelhanças entre hospitalidade e carnaval, segundo Sheringham e Daruwalla (2007), como a inversão da ordem, o senso de desordem, o caráter temporário, a criação de vínculos, a fuga do cotidiano, a transgressão autorizada das fronteiras e a comensalidade. Há um consenso para reordenar e assumir os papéis e obrigações prescritas e essa suspensão temporária das hierarquias permite, nos dois casos, a mudança na interação entre os envolvidos.

A hospitalidade é compreendida, de acordo com Montandon (2011, p. 31), como uma maneira de interação social, podendo ser entendida também como uma "forma própria da hominização" ou ao menos como uma das principais formas de sociabilidade. Ela se caracteriza como um meio de viver em sociedade, conduzido por regras, leis e rituais. 
Um ritual é composto por um conjunto de regras e etiquetas, caracterizando-se como um agrupamento de comportamentos simbólicos repetidos. No caso da hospitalidade, o ritual controla as relações sociais e é composto por uma série de cenas que envolvem dois atores centrais: o visitante e o anfitrião, cada qual com seu papel definido, em um tempo e espaço precisos. O ritual tem início com um convite ou com um pedido de acolhimento, sucedido pela cena da soleira, que simboliza uma fronteira entre o exterior e o interior na qual o visitante deve aguardar a permissão para transpor. Ao transpor essa fronteira, ele é aceito e introduzido no espaço do anfitrião e dali em diante as cenas são marcadas por uma constante troca de dádivas e contradádivas (CAMARGO, 2015).

Homero (apud MONTANDON, 2011), decretou as regras do ritual da hospitalidade, desde a chegada até a partida do visitante. As regras são compostas de microcenas que incluem: a chegada, a recepção, a oferta de alimentos e bebidas, dizer o nome e a pátria, banhar-se, deitar-se, a troca de presentes e também as despedidas. Tudo se desenrola como um ritual, com uma ordem determinada. Entretanto, a hospitalidade não se reduz ao oferecimento de alimentos, bebidas e abrigo: a relação entre as pessoas construída por meio dela acarreta em um vínculo social e se apoia em valores de sociabilidade e solidariedade.

A quadra da escola de samba Camisa Verde e Branco é uma referência para seus membros e para os moradores do entorno, e é considerada, pela comunidade, como uma extensão de sua casa ou até uma segunda casa, já que é ali que ela ensaia para o carnaval, se encontra, se reúne, convive, se diverte, samba e faz samba, em um processo de criação e fortalecimento dos vínculos sociais e dos laços afetivos. Ela é utilizada também para pequenas confraternizações - nas quais, cada um, dentro de sua possibilidade, leva alimentos e/ou bebidas - e comemorações de aniversário. Nessas ocasiões, a quadra se caracteriza como um local de partilha, função que contribui para o estreitamento dos laços sociais.

A comunidade da escola de samba é um grupo unido que se identifica e compartilha interesses comuns, como o samba e o amor e lealdade à agremiação e conta com um grupo menor e mais restrito em seu interior, conhecido como família. Entre os indivíduos da chamada família, os vínculos sociais e a lealdade são ainda mais intensos. Constatou-se que há uma classificação interna e não oficial que distingue os membros e frequentadores do Camisa em três categorias, de acordo com seu grau de envolvimento: sambista, sambeiro e turista. O primeiro é o membro que faz parte da família; o segundo é o sócio que, embora participe das atividades carnavalescas, não possui a mesma lealdade do primeiro; e o terceiro é aquele que não tem nenhum envolvimento com a comunidade e participa apenas do desfile de carnaval e, às vezes, de alguns ensaios também. É esse sambista quem define o outro, o forasteiro, o turista e também o irmão.

As classificações sambista e sambeiro são originárias da década de 1920, de acordo com Leopoldi (1978), e eram, inicialmente, empregadas para designar a aptidão ou não de uma pessoa para desenvolver uma coreografia específica no ritmo do samba. Sambista era a pessoa que conseguia executar com habilidade uma sequência coreográfica e sambeiro, ao contrário, era quem se atrevia a sambar sem saber fazê-lo somente para se exibir. O sambeiro também era chamado de falso sambista ou presepeiro, e até a consolidação das escolas de samba do Rio de Janeiro o termo não possuía conotação negativa e era pouco empregado. Posteriormente, ganhou um novo significado e passou a designar as pessoas que se inseriam em uma agremiação carnavalesca a fim de obter oportunidade para promoções sociais. Atualmente, sambista e sambeiro referem-se a duas categorias relacionadas com o mundo do samba, sendo, respectivamente, uma que canta, toca e dança o samba com uma naturalidade de berço e outra constituída por pessoas apenas interessadas em participar do desfile de carnaval, mas que não possuem grande convivência com o mundo do samba. Em alguns dicionários, confunde-se sambista com sambeiro, o que é inaceitável no mundo do samba. 
Por um lado, a participação de qualquer pessoa alheia ao mundo do samba é aceita pelas agremiações, uma vez que isso as beneficia por aumentar o número de membros e melhorar o desfile carnavalesco (já que as escolas de samba precisam apresentar-se com um número mínimo de componentes, que varia, em São Paulo, de mil a dois mil, dependendo se a agremiação está no Grupo de Acesso ou no Grupo Especial, respectivamente, e perdem ponto se o número for inferior ao estipulado) e também o fato de acolher pessoas dos estratos mais elevados da população confere-lhes uma imagem de ascensão social. Por outro, espera-se que esse convívio não acarrete em violência aos sentimentos de consideração e respeito dos sambistas ao samba (LEOPOLDI, 1978).

Para a comunidade do Camisa Verde e Branco, turistas são quaisquer pessoas que, não sendo sócios, apresentam-se na quadra para os ensaios raramente e/ou apenas nas semanas que antecedem o desfile carnavalesco. Eles não possuem qualquer tipo de vínculo e não integram a família. Os turistas são bem-vindos, embora a agremiação não desenvolva nenhuma ação com o intuito de captá-los e fazê-los participar dos ensaios e, na maioria das vezes, eles praticamente não são notados pela comunidade. Há os turistas que frequentam os ensaios esporadicamente por se identificarem com o samba ou com o carnaval, podendo ou não participar do desfile, e também aqueles que compram a fantasia e participam apenas do desfile, sem participar dos ensaios. A participação de turistas estrangeiros acontece em alguns ensaios, geralmente em datas próximas ao carnaval, e percebe-se um cuidado especial com eles. Normalmente, há uma pessoa designada para acompanhá-los, que os recebe e os leva até um camarote exclusivo.

Um turista pode ultrapassar a fronteira material da agremiação e, ao mesmo tempo, confrontar-se com o limite imaterial, de acordo com Raffestin (1997). Ou seja, embora ele esteja dentro da quadra e possa assistir ao ensaio, ele não integra a comunidade, não faz parte daquela família e continua sendo um estranho. Para passar do estatuto de turista para o de sambista e ser aceito na comunidade é preciso ultrapassar as fronteiras abstratas. Sua transformação em sambista significa que, de ser evitado e tratado com hostilidade, ele deve ser honrado e protegido, pois passou a integrar a comunidade. No Camisa não há nenhuma regra para a conversão do turista em convidado e somente por meio da convivência, da confiança ou da proximidade com algum membro da agremiação, um forasteiro pode, talvez, passar a integrar a família.

Essa família vai além do núcleo familiar e as pessoas identificam-se umas com as outras pelas condições sociais de existência, pela raça, pelos gostos e hábitos comuns e em alguns casos por morarem no mesmo bairro. No entanto, o principal motivo para tal afinidade é o amor e dedicação à escola. Constatou-se, por meio das entrevistas realizadas, que a família é composta, em sua maioria, por pessoas que frequentam a agremiação há tempos e de descendentes de famílias fundadoras e que possuem algum cargo, seja na diretoria ou na coordenação das alas que compõem o desfile carnavalesco. O crescimento e a renovação da família acontecem, em muitos casos, por hereditariedade - já que é uma agremiação familiar, da qual diversos membros da mesma família participam - e também quando algum de seus membros leva um parente ou amigo para participar e este acaba se integrando à comunidade.

Pertencer ao Camisa é fazer parte da família, participar das ações para o carnaval, ter amor e lealdade ao pavilhão, comparecer às festas particulares dos membros, visitar a casa dos amigos feitos lá e frequentar a quadra mesmo quando não há atividade no local. Pertencem à família os membros antigos, aqueles que entraram por possuírem relação de parentesco com um membro estabelecido ou, em alguns casos, por indicação de algum deles. Os membros convivem juntos há tempos e possuem vínculos de amizade entre si; já os turistas não se conhecem, não conhecem os membros da comunidade e não possuem, normalmente, qualquer vínculo entre si, com os membros ou com a agremiação. 


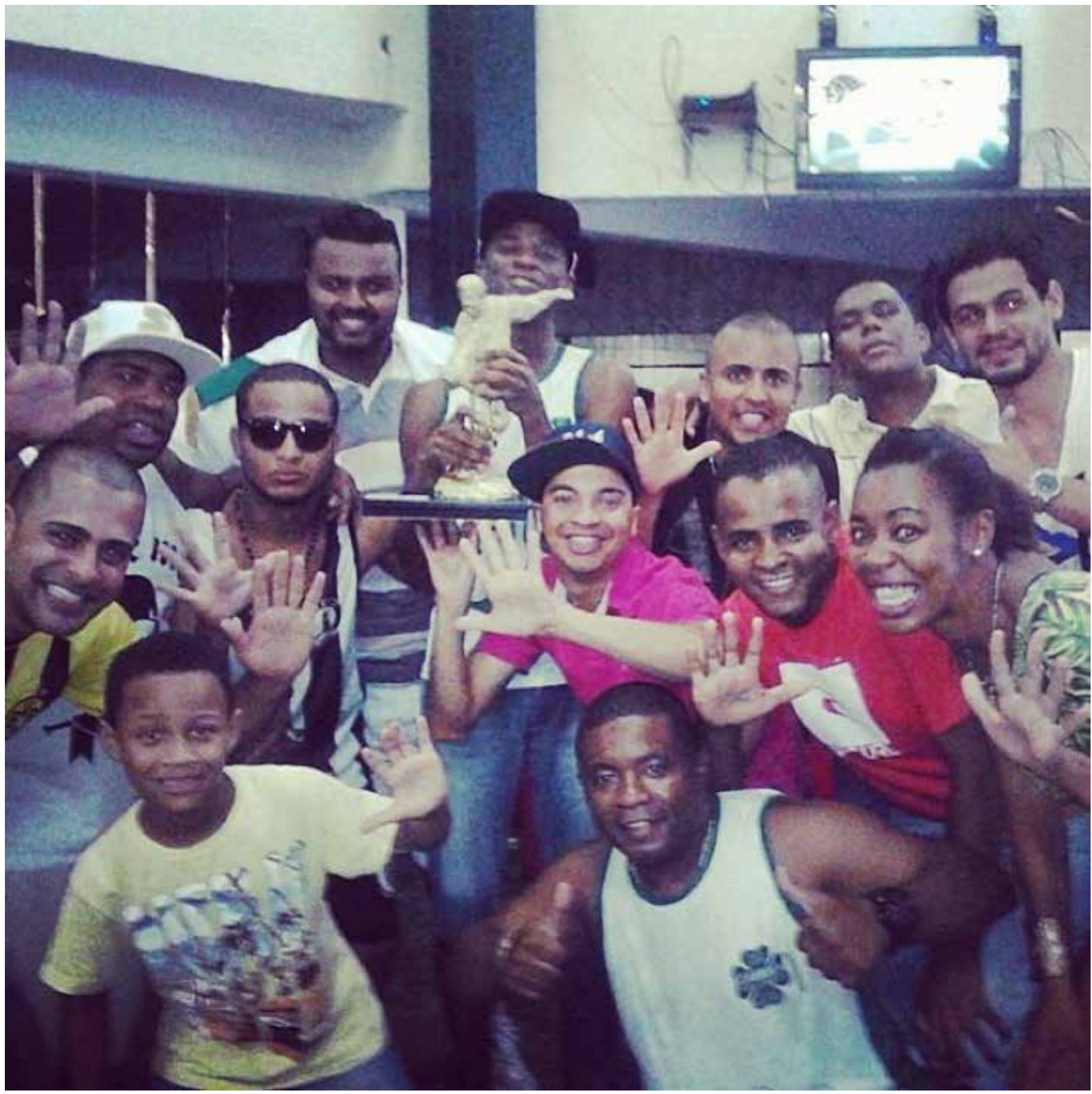

\section{A Figura 1 mostra alguns membros da agremiação reunidos na quadra de ensaios em um momento de comemoração.}

Fonte: Camisa Verde e Branco - Oficial (2014)

A integração entre os membros da família, o amor ao pavilhão e a frequência com que os membros se reúnem na quadra de ensaios foram observados nas visitas à agremiação, nas participações nos eventos e relatados nas entrevistas. O diretor de carnaval, que é membro desde 1982 dessa agremiação, disse ter estabelecido muitos contatos no Camisa Verde e Branco, que criaram vínculos, ter levado muitos amigos para lá, que o amor à agremiação é inexplicável - algo como uma doença incurável - e que como viu a evolução da escola, desde quando a quadra era de chão de terra e não tinha teto, sente que é uma extensão de sua casa, um quarto a mais que ele tem. Ele também contou que não tem dia certo para ir à quadra, que às vezes passa de carro e entra para tomar um café e, no período de carnaval, vai todos os dias. Uma das coordenadoras de ala relatou que ali fez muitas amizades sinceras e para o resto da vida, que a quadra é sua segunda casa e a comunidade sua segunda família e também que os membros utilizam a quadra para a realização de festas, aniversários e até chá de bebê por ser um lugar de fácil acesso para todos. 
A antiga porta-bandeira considera a comunidade como sua família porque muitas vezes passa mais tempo na quadra do que na sua própria casa e afirmou que a relação com a escola é uma coisa de emoção e coração e que os membros costumam dizer que matam e morrem pelo pavilhão. Ela relatou que o Camisa é uma escola de tradição que procura trabalhar e desfilar somente com sua comunidade, sem muitas pessoas de fora, e que as festas, as comemorações de aniversário e até a reunião de Natal são realizadas na quadra. Eles se consideram uma família mesmo, pois tudo é comemorado lá. O antigo mestre-sala, que exerceu a função durante 14 anos e atualmente é coordenador do setor de casais, destacou o vínculo que tem com a comunidade, contou que isso é importante e que quem não faz parte da escola de samba não entende como se dá a participação dos membros. Ele considera a quadra uma extensão de sua casa, já que passa tanto ou até mais tempo lá do que em sua própria casa, e que vai até lá mesmo quando não há atividade relacionada à agremiação. De acordo com ele, a atividade que tem dentro do samba faz com que crie um vínculo que é muito difícil de separar, principalmente, quando se é benquisto por todo mundo.

O vice-presidente da agremiação é da comunidade há 26 anos e já passou, segundo ele, por todos os setores, incluindo bateria, comissão de carnaval e harmonia. Ele contou que reside no bairro da Vila Carolina, local que concentra, segundo ele, muitas pessoas do Camisa Verde e Branco, o que o levou a começar a frequentar a agremiação. Seu vínculo com a escola é grande e ele alega ter feito muitas amizades lá. A comunidade é considerada, para ele, uma família, a quadra é sua segunda casa e na época de carnaval, ele chega, algumas vezes, a se afastar da família pelo fato de passar bastante tempo na quadra. O local funciona também, para ele, como um ponto de encontro para os membros. O mestre de bateria, com um de seus irmãos, frequenta o Camisa desde criança e contou que vai à quadra quase que diariamente se encontrar com os amigos e/ou cuidar e arrumar os instrumentos da bateria, que a quadra se torna sua casa durante o carnaval e que seu vínculo com a comunidade é grande. Seu pai foi mestre de bateria durante 20 anos nessa agremiação e foi uma questão de tempo para que o pai se aposentasse e ele assumisse o cargo. A transmissão da liderança da bateria depende da presidência da escola e para alguém participar pela primeira vez é necessário haver vaga disponível, o que acontece quando um ritmista deixa o cargo. Havendo vaga para um novo ritmista, o mestre de bateria escolhe a pessoa mais apta entre as que estão na lista de espera - da qual para participar basta saber tocar algum instrumento.

Dentro da comunidade e da família, os apelidos são tão importantes para a identificação que poucas pessoas são conhecidas por seus verdadeiros nomes e até no organograma alguns nomes encontram-se sucedidos pelos apelidos. Pode-se interpretar esse tratamento como um canal de entrelaçamento que concorre para que se possa vê-los como integrantes de uma verdadeira comunidade e também a intimidade e a integração existentes entre os membros configuram uma rede de amizade e de cooperação que é por eles chamada de família.

No organograma, a autoridade máxima é representada pelo presidente Hervando Luiz Veloso, conhecido como Veloso, seguido do vice-presidente Washington Alessandro, conhecido como Adão. Abaixo, ficam os demais cargos, que respondem diretamente à diretoria: diretor-geral, harmonia, patrimônio, planejamento, eventos, financeiro, jurídico, musical, bateria, ouvidoria/qualidade, projeto social, secretaria, cerimonial, imprensa, esportes, marketing, pessoal/treinamento, conselho fiscal e comissão de carnaval (CAMISA, 2015).

Ele também não institui a figura do anfitrião, a qual, por dedução, estaria centrada no presidente. Na prática, é ele quem dá as boas-vindas aos convidados nos eventos oficiais da escola, no entanto, no dia a dia, nos encontros informais e não planejados e até mesmo em alguns ensaios, o presidente nem sempre 
está presente e o exercício do receber não é delegado a ninguém. Constatou-se que como o foco é o desfile, a hierarquia é pensada somente para essa ocasião e não reproduz o cotidiano.

\section{Considerações finais}

A quadra da escola de samba Camisa Verde e Branco é um local de hospitalidade, de encontro, de convivência e de sociabilidade para sua comunidade e se constitui em um local onde seus membros se reúnem, trocam experiências e fortalecem a amizade. Os ensaios para o carnaval e demais eventos realizados no local auxiliam a promoção dos vínculos sociais. Embora nem todos os membros morem na Barra Funda ou nos bairros vizinhos, há um sentimento de pertencimento a ele e à agremiação, e nos hinos, nos sambas-enredos e nas publicações nas redes sociais é comum a exaltação ao bairro em que a escola está localizada. É provável que os vínculos não fossem tão sólidos e estáveis caso não houvesse um espaço que promovesse o encontro e a convivência dos membros. Foi constatado que a agremiação se constitui em uma família, na qual predomina um ambiente solidário e acolhedor, e que a quadra é por eles considerada uma segunda casa, já que alegam passar, muitas vezes, a maior parte de seu tempo lá, principalmente na época do carnaval. Percebeu-se, por meio de conversas, entrevistas e de fotos e publicações nas redes sociais, que as pessoas se encontram frequentemente na quadra, mesmo que não haja nenhuma atividade relacionada à escola, ou na casa de algum dos membros.

Os membros possuem um sentimento de lealdade, de solidariedade e de identificação com a agremiação, com a música (o samba) e com o bairro. A comunidade do Camisa Verde e Branco é estruturada por meio de relações de parentesco, sendo comum membros de uma mesma família participarem, cada qual desempenhando um papel, seja na diretoria ou na coordenação das alas do desfile de carnaval, de vizinhança (já que alguns membros residem na Vila Carolina, bairro da zona norte de São Paulo) e de amizade.

Há uma mudança do ritual da hospitalidade da escola para o Sambódromo e também quando o carnaval se aproxima. Nos ensaios técnicos realizados no Sambódromo há a participação de um número maior de pessoas do que nos ensaios na quadra e, como as pessoas se juntam e se misturam, é difícil distinguir membros de não membros. No carnaval, exceto diretoria e coordenadores de ala, estão todos fantasiados e, dentro de uma mesma ala, todos são iguais. Nessas ocasiões, o ritual muda e todos são tratados da mesma maneira, sejam membros ou não, pertencentes à família ou não.

A exigência, imposta no regulamento oficial dos desfiles carnavalescos, de um número mínimo de componentes (no caso do Grupo de Acesso, do qual o Camisa faz parte, o mínimo são mil pessoas), obriga a agremiação a receber turistas, os quais, por não possuírem vínculos, não se sentem acolhidos. Ressalta-se a importância do papel do anfitrião no ritual da hospitalidade, uma vez que ele é o responsável por receber os visitantes. No caso do Camisa Verde e Branco, no cotidiano, a figura do anfitrião não é formalizada, pelo contrário, encontra-se diluída e não há a tomada de consciência, por parte de cada um dos membros, da necessidade de recepcionar os turistas e do exercício da hospitalidade. Analisando o organograma, deduz-se que, teoricamente, a figura do anfitrião está centrada no cargo de presidente, que é a autoridade máxima, no entanto, na prática, o exercício dessa função não é delegado a ninguém.

Acredita-se que a comunidade pretenda manter seu caráter familiar, evitando a expansão da chamada família e talvez por isso não haja ações destinadas a acolher ou integrar o turista, que é admitido e tolerado 
por ocasião do desfile de carnaval. Os turistas dificilmente ultrapassarão a fronteira imaterial da agremiação, a não ser por indicação de alguém da família, e, muitas vezes, são incluídos somente no momento do desfile carnavalesco. Em uma ocasião normal, o turista, embora admitido na quadra durante um evento ou ensaio, mediante o pagamento da entrada, geralmente, não é notado pela comunidade, não se sente acolhido e permanece isolado. No entanto, com o passar do tempo e a frequência na participação de ensaios, ele passa a ser percebido por alguns membros, mas continua invisível para a maioria.

A agremiação parece reservar, em algumas alas, a transmissão dos cargos para as pessoas da família e renovar-se por hereditariedade ou, em alguns casos, quando um turista é apresentado e apadrinhado por um membro estabelecido, o qual por ele se responsabiliza. A transmissão do comando da bateria e a participação como ritmista ilustram essa questão, já que o atual mestre de bateria parece ter assumido a direção pelo fato de seu pai ter ocupado esse cargo durante muito tempo e por ser ele quem escolhe quem irá participar do desfile de carnaval como ritmista. No dia do carnaval, o turista é acolhido de tal forma que se sente como integrante da agremiação, porém, após o término do desfile e do recesso que se segue, a situação volta a se normalizar, ele voltará a não ser notado e será percebido como um intruso.

Por se tratar de uma pesquisa qualitativa, o corpus analisado não pode ser generalizado e as conclusões são válidas apenas para o conjunto entrevistado. Nesse sentido, para esse grupo, a exclusão do turista não é absoluta, mas é predominante.

\section{Referências}

BAUER, M. W.; AARTS, B. A construção do corpus: um princípio para a coleta de dados qualitativos. In: BAUER, M. W.; GASKELL, G. (ed.). Pesquisa qualitativa com texto, imagem e som: um manual prático. 4. ed. Petrópolis-RJ: Vozes, 2002. Cap. 2.

BELO, V. D. L. 0 enredo do carnaval nos enredos da cidade: dinâmica territorial das escolas de samba em São Paulo. Dissertação (Mestrado em Geografia Humana) - Faculdade de Filosofia, Letras e Ciências Humanas. Universidade de São Paulo. São Paulo, 2008.

BRITTO, I. M. Samba na cidade de São Paulo (1900-1930): um exercício de resistência cultural. São Paulo: FFLCH/USP, 1986.

BUENO, M. S. (org.). Hospitalidade no jogo das relações sociais. Goiânia: Editora Vieira, 2008.

CAMISA VERDE E BRANCO. Associação Cultural e Social Escola de Samba Mocidade Camisa Verde e Branco. Disponível em: 〈http://www.camisaverde.net/〉. Acesso em: 22 dez. 2014.

CAMISA VERDE E BRANCO. Camisa Verde e Branco - Oficial. Facebook, 2014. Disponível em: 〈https:// www.facebook.com/CamisaVerdeOficial〉. Acesso em: 10 nov. 2014.

FRIESE, H. The Limits of Hospitality. Paragraph, Edinburgh, v. 32, p. 51-68, março 2009. ISSN $0264^{-}$ 8334 .

GIL, A. C. Métodos e técnicas de pesquisa social. 6. ed. São Paulo: Atlas, 2011.

GOTMAN, A. 0 turismo e a encenação da hospitalidade. In: CAMARGO, L. O. D. L.; BUENO, M. L. (org.). Cultura e consumo: estilos de vida da contemporaneidade. São Paulo: Editora Senac, 2008. 
GRASSI, M.-C. Hospitalité. Passer lê seuil. In: MONTANDON, A. Le livre de l'hospitalité. Accueil de l'étranger dans l'histoire et les cultures. Paris: Bayard, 2004.

LAPLANTINE, F. A descrição etnográfica. São Paulo: Terceira Margem, 2004.

LEOPOLDI, J. S. Escola de samba: ritual e sociedade. Petrópolis: Editora Vozes Ltda., 1978.

MONTANDON, A. Espelhos da hospitalidade. In: MONTANDON, A. (org.). 0 livro da hospitalidade: acolhida do estrangeiro na história e nas culturas. São Paulo: Senac, 2011.

OBSERVATÓRIO DO TURISMO / SÃO PAULO TURISMO. Censo (100 anos) do samba paulistano. 3. ed. São Paulo: São Paulo Turismo, 2014a. Disponível em: 〈http://www.youblisher.com/p/844000Censo-100-anos-do-Samba-Paulistano/>. Acesso em: 15 jul. 2014.

PIMENTEL, A. B. et al. Dádiva e Hospitalidade. Caderno Virtual de Turismo, Rio de Janeiro, v. 7, n. 3, p. 26-34, 2007.

PITT-RIVERS, J. The law of hospitality. HAU: Journal of Ethnographic Theory, v. 2, n. 1, 19 junho 2012. 501-517. Disponivel em: 〈http://www.haujournal.org/index.php/hau/article/view/99/120〉. Acesso em: 16 ago. 2013.

QUEIROZ, M. I. P. D. Carnaval brasileiro: o vivido e o mito. São Paulo: Brasiliense, 1999.

RAFFESTIN, C. Réinventer l’hospitalité. Communication, Paris, 65, 1997. 59-68.

SEBE, J. C. Carnaval, carnavais. São Paulo: Editora Ática, 1986.

SEVERINO, A. J. Metodologia do trabalho científico. 23. ed. rev. e ampliada. São Paulo: Cortez, 2007.

SHERINGHAM, C.; DARUWALLA, P. Transgressing Hospitality: Polarities and Disordered Relationship? In: LASHLEY, C.; LYNCH, P.; MORRISON, A. Hospitality: A Social Lens. Oxford: Elsevier, 2007. Advances in Tourism Research series.

SIMSON, O. R. D. M. V. Carnaval em branco e negro: carnaval popular paulistano - 1914-1988. Campinas: Ed. Unicamp - Imprensa Oficial de São Paulo, v. 1, 2007. 